\title{
CUA Guidelines on antibiotic prophylaxis for urologic procedures
}

\author{
Marko Mrkobrada, MD; ${ }^{*}$ Ivan Ying, MD, FRCPC,; Stephanie Mokrycke, BSc; George Dresser, MD, FRCPC; \\ Sameer Elsayed, MD, FRCPC,; Varunkumar Bathini, MD, FRCSC; ${ }^{\dagger}$ Erin Boyce, BA MLIS, ${ }^{*}$ Patrick Luke, MD, FRCSC ${ }^{\dagger}$
}

"Department of Medicine, Schulich School of Medicine, London Health Science Centre, London, ON; 'Department of Surgery, Schulich School of Medicine, London Health Science Centre, London, ON

Cite as: Can Urol Assoc J 2015;9(1-2):13-22. hittp://dx.doi.org/10.5489/cuai.2382

Published online February 5, 2015.

\section{Introduction}

\section{Need for guidelines}

Guidelines are available for the use of antimicrobial prophylaxis in open operative procedures to prevent postoperative wound infections. ${ }^{1}$ However, the field of urology uses unique surgical approaches to treat various urologic conditions. Quite often, our approach does not require incisions; instead we use transluminal (endoscopy and catheter manipulation), transrectal (biopsy of the prostate) and/or completely non-invasive (extracorporeal shock wave lithotripsy [ESWL]) techniques. In urologic procedures, infections may arise not only from skin or rectal flora, but also from organisms in the vicinity of the operative site (i.e., struvite stones, subclinical prostatitis, pre-existing Foley catheters and stents). The sequelae of these infections can have devastating consequences, including significant morbidity and even death.

The American Urological Association provides a Best Practice Policy Statement of Urologic Surgery Antimicrobial Prophylaxis. ${ }^{2}$ To provide a Canadian perspective, the Canadian Urological Association (CUA) Guidelines Committee approached our panel to provide rigorous evidence-based guidelines on the use of antimicrobial prophylactic therapy in urologic procedures that would be applicable in Canada. We concentrated our efforts on areas unique to urology, including urinary tract manipulation, stone surgery, endoscopic surgery and transrectal biopsy of the prostate (TURP). The evidence was then assessed and presented according to best standards of practice.

\section{Methods}

\section{Objectives}

Our objective was to develop a set of evidence-based guidelines for the use of antibiotic prophylaxis during urologic procedures. A panel of clinicians and librarians was assembled, and the following pertinent clinical areas were identified:

- Antibiotic prophylaxis for transrectal biopsy of the prostate (TRBP)

- Antibiotic prophylaxis for ESWL

- Antibiotic prophylaxis for non-ESWL stone manipulation procedures (percutaneous nephrolithotomy $[\mathrm{PCNL}]$ and ureteroscopy)

- Antibiotic prophylaxis for urologic endoscopic procedures, excluding stone manipulation

- Antibiotics for TURP

The panel selected these areas because they focus on clinical questions specific to the discipline of urology, and for which there is a lack of published evidence-based guidelines.

\section{Systematic review methods}

With the aid of a librarian experienced in medical literature searches, a panelist performed a literature review to identify high-quality systematic reviews on the topic. If no systematic review was identified, one was performed according to PRISMA (Preferred Reporting Items for Systematic Reviews and Meta-Analyses) guidelines. ${ }^{3}$

\section{Eligibility criteria}

We included only randomized controlled trials (RCTs) that evaluated antibiotic prophylaxis prior to urologic procedures 
Mrkobrada et al.

in patients who did not have a known pre-procedural infection.

\section{Information sources}

A librarian experienced in conducting systematic reviews in the healthcare field assisted us in conducting our search. We electronically searched the following bibliographic databases: EMBASE (January 1980 to October 2012), Medline (January 1950 to October 2012) and All evidence-based medicine (EBM) reviews (ACP Journal Club, Database of Abstracts of Reviews of Effects, Cochrane Central Register of Controlled Trials, Health Technology Assessment, Cochrane Database of Systematic Reviews, National Health Service Economic Evaluation and Cochrane Methodology Register, from inception of database to October 2012). There was no language restriction. We identified relevant papers from the grey literature by consulting with experts in the field. Our searches were supplemented by reviewing the reference lists of all citations that met our final inclusion criteria.

\section{Study selection}

We entered the retrieved citations into RefMan $\mathrm{v} 12$, and duplicate records were removed. Two investigators independently screened the title and abstract of the citations. If either investigator felt that a citation might be relevant, it was marked for full-text retrieval. Two investigators independently evaluated the retrieved full-text articles for eligibility. Cohen's kappa statistic was used to quantify agreement between the investigators. Disagreements were resolved through a consensus process of having the two reviewers discuss their decisions, and a third investigator was consulted in case of an impasse to provide a final decision.

\section{Data collection}

Two reviewers independently abstracted the data from included trials. Any disagreement in the abstracted data between the two reviewers was resolved through the same consensus process used in study selection.

The following data items were abstracted from the articles included in the systematic review: Demographic data, study interventions and the study outcomes of mortality, bacteriuria, bacteremia, urinary tract infection, fever, septicemia, pyuria and adverse events. We used the study's definition of the outcome.

\section{Risk of bias}

We assessed for the risk of bias in the included trials by determining the adequacy of allocation concealment, along with blinding of the trial participants, care providers, and outcome assessors. We also assessed whether the trial was terminated prematurely due to benefit, and whether the analysis was conducted according to the intention-to-treat principle. We also used the GRADE (Grading of Recommendations Assessment, Development and Evaluation) approach to assess the quality of evidence. ${ }^{4}$

\section{Statistical analyses}

For each trial outcome, we calculated the relative risk (RR) to summarize the outcomes for patients treated with antibiotics versus placebo or no treatment. For all relative risks, we determined $95 \%$ confidence intervals. We pooled results using a random-effects model. We quantified statistical heterogeneity using the I2 statistic. We interpreted an I2 value of $0 \%$ to $25 \%$ as low heterogeneity, $25 \%$ to $50 \%$ as moderate heterogeneity, and greater than $50 \%$ as high heterogeneity. The risk of publication bias across trials was assessed using funnel plots.

\section{Development of evidence-based guideline recommendations}

The panel convened to make a draft of the guideline recommendations. This draft was presented to the CUA Guidelines Committee.

\section{Guideline findings and recommendations}

\section{Antibiotic prophylaxis for transrectal prostate biopsy}

\section{Results of literature search}

Our literature search identified recently-published systematic review of high methodological quality based upon the PRISMA Statement. ${ }^{5}$ We based our recommendations on the findings of this systematic review.

\section{Results of the systematic review}

The systematic review identified a total of 9 RCTs (3599 patients) comparing antibiotics with control treatment. ${ }^{5}$ Fluoroquinolones were studied most frequently (5 RCTs, 1188 patients).

There was a high incidence of adverse infection-related events in patients undergoing TRPB without antibiotic prophylaxis. Compared with untreated controls, antibiotics significantly reduced the rates of bacteriuria $(14.8 \%$ vs. $3.9 \%)$; bacteremia ( $8.6 \%$ vs. $2.1 \%$ ); fever $(10.8 \%$ vs. $4.0 \%$ ); urinary tract infection (UTI) $(9.0 \%$ vs. $3.3 \%)$; and hospitalization (3.3\% vs. $0.3 \%$ ). No adverse events related to antibiotic prophylaxis were recorded. 
With respect to short ( 1 day) versus long (3 days) course regimens, the only significant difference was a decreased incidence of bacteriuria in the 3-day group. However, the differences between the groups were not significant with regards to bacteremia, fever, UTI and hospitalization. In the analysis between single dose and multiple doses, multiple doses were associated with significantly reduced rates of bacteriuria, without any effect on other outcomes. Also, there was no difference between oral versus systemic administration of the antibiotics.

\section{Antibiotic class}

In studies comparing different classes of antibiotics (i.e., fluoroquinolones, sulfonamides, or piperacillin/tazobactam versus other antibiotics), there were no differences in outcomes. The best evidence exists for quinolones as they were the most commonly utilized and analyzed, and had the largest number of patients included in the various trials. With emerging quinolone resistances, novel approaches using multi-agent and perirectal cultures to determine appropriate antibiotic selection have been used. ${ }^{6,7}$ Although further RCTs are required before recommending this approach universally, we recommend that patients with increased risk of harboring resistant organisms (previous history of urosepsis, or multiple treatments with antibiotics) should have perirectal culture swabs performed prior to biopsy.

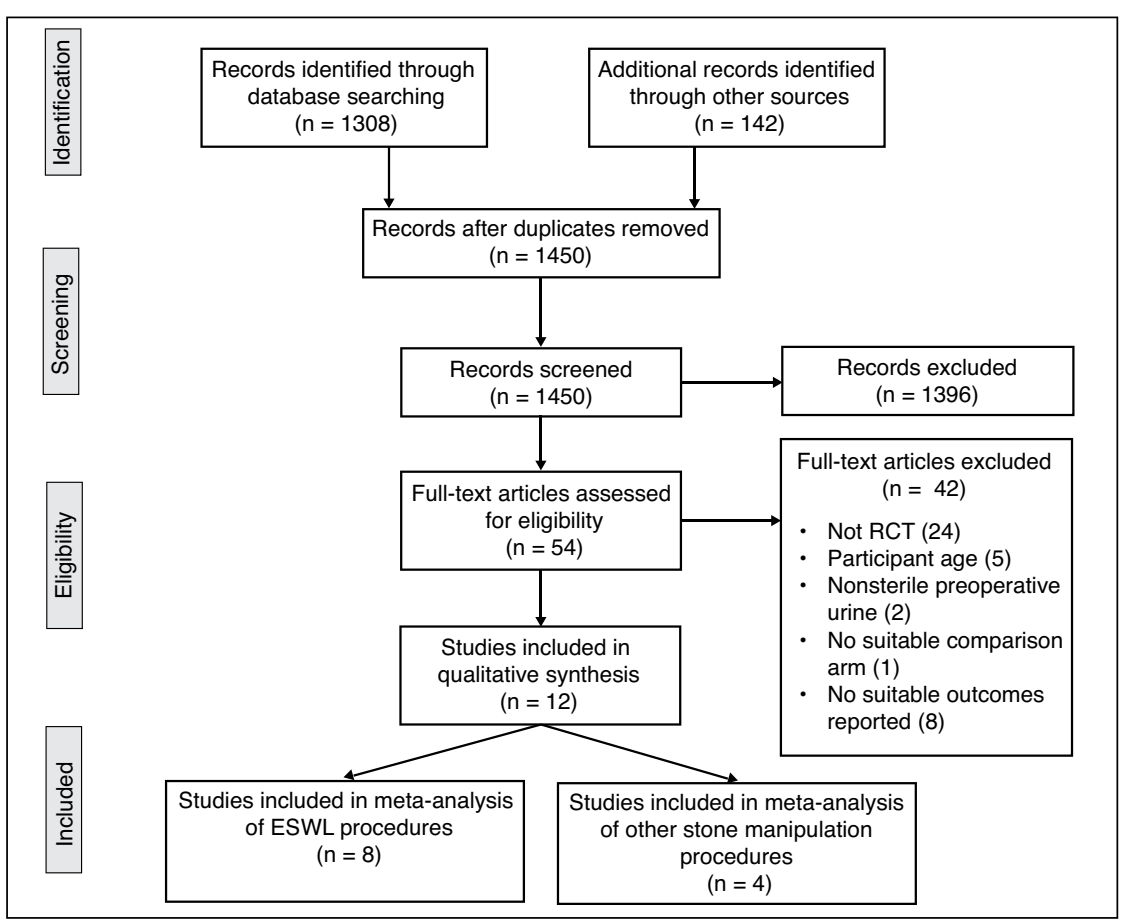

Fig. 1. Study selection flowsheet for extracorporeal shock wave lithotripsy and other stone manipulation procedures. RCT: randomized controlled trial.
With regards to antibiotics versus enema or antibiotic versus antibiotic and enema, only 4 trials were analyzed with limited number of patients in each trial. There was no evidence that pre-procedural enemas affected infection rates.

\section{Guideline recommendations}

There is a high risk of adverse infection-related events in patients undergoing TRPB, and prophylactic antibiotics are recommended for these patients (Grade A, Level of Evidence IA). Most studies investigated the use of fluoroquinolones; single dose or short-courses of antibiotics appear to be as effective as the longer course regimens. There was insufficient evidence for efficacy of pre-procedural enemas to recommend their routine use. The choice of specific agent for prophylaxis should be based, in part, on the local epidemiology of drug resistance in potential uropathogens (Grade D, Level of Evidence IV). In patients at increased risk of harboring resistant organisms, perirectal culture swabs prior to TRPB should be considered.

\section{Antibiotic prophylaxis for ESWL}

\section{Methods of literature search}

We included all RCTs comparing the use of antibiotic prophylaxis versus control. Study participant inclusion criteria involved adults with preoperative sterile urine who underwent ESWL. We excluded participants with positive preoperative urine cultures. The primary outcomes of interest were postoperative infectious complications of UTI, fever, or any other serious infectious complication. We excluded trials that did not report on these outcomes of interest.

\section{Results of the systematic review}

The literature search identified 1450 citations, and we selected 54 articles for fulltext retrieval (Fig. 1). Eight met the eligibility criteria for final inclusion in the systematic review. ${ }^{8-15}$

Eight controlled trials randomized a total of 940 study participants (Table 1 ). The incidence of UTI and fever were $4.2 \%$ and $3.4 \%$, respectively. Antibiotic prophylaxis in patients undergoing ESWL (Fig. 2, Fig. 3) was not associated with a statistically significant difference in the risk of post-procedural UTI (RR 0.76, $95 \% \mathrm{Cl}, 0.39$ to $1.48, p=0.42$ ), or an inci- 
Mrkobrada et al.

\begin{tabular}{|c|c|c|c|c|c|c|c|c|}
\hline Author & Year & Procedure & $\mathbf{N}_{\text {tot }}$ & Control & Antibiotic & Route & $\begin{array}{l}\text { Total dose } \\
(\mathbf{m g})\end{array}$ & Dosing regimen \\
\hline \multirow{6}{*}{ Bierkens } & \multirow{6}{*}{1997} & \multirow{6}{*}{ ESWL } & \multirow{6}{*}{177} & \multirow{6}{*}{ Placebo } & Ciprofloxacin & IV & 200 & 1 dose 30 min before surgery \\
\hline & & & & & \multirow{5}{*}{ Cefuroxime } & IV & 200 & 1 dose 30 min before surgery \\
\hline & & & & & & PO & 3000 & 2 doses/day for 6 days after surgery \\
\hline & & & & & & IV & 750 & 1 dose 30 min before surgery \\
\hline & & & & & & IV & 750 & 1 dose $30 \mathrm{~min}$ before surgery \\
\hline & & & & & & PO & 3000 & 2 doses/day for 6 days after surgery \\
\hline Claes & 1989 & ESWL & 181 & $\begin{array}{l}\text { No } \\
\text { treatment }\end{array}$ & $\begin{array}{l}\text { Amoxicillin/ } \\
\text { clavulanate }\end{array}$ & IV & $2000 / 200$ & 1 dose $30 \mathrm{~min}$ before surgery \\
\hline Dejter & 1989 & ESWL & 49 & Placebo & Norfloxacin & PO & 2000 & $\begin{array}{c}1 \text { dose every } 12 \text { hours beginning } 48 \\
\text { hours before surgery }\end{array}$ \\
\hline \multirow{2}{*}{ Ghazimoghaddam } & \multirow{2}{*}{2011} & \multirow{2}{*}{ ESWL } & \multirow{2}{*}{150} & \multirow{2}{*}{$\begin{array}{l}\text { No } \\
\text { treatment }\end{array}$} & Co-trimoxazole & PO & $400 / 80$ & Unclear \\
\hline & & & & & Nitrofurantoin & PO & 100 & Unclear \\
\hline Herrlinger & 1987 & ESWL & 64 & $\begin{array}{l}\text { No } \\
\text { treatment }\end{array}$ & Azlocillin & IV & 5000 & $\begin{array}{c}1 \text { dose } 30 \text { min before surgery } \\
\text { continued until } 6 \text { to } 8 \text { hours after } \\
\text { surgery }\end{array}$ \\
\hline Knipper & 1989 & ESWL & 50 & $\begin{array}{l}\text { No } \\
\text { treatment }\end{array}$ & Enoxacin & PO & 400 & 1 dose 1 hour before surgery \\
\hline \multirow{2}{*}{ Pettersson } & \multirow{2}{*}{1989} & \multirow{2}{*}{ ESWL } & \multirow{2}{*}{149} & \multirow{2}{*}{$\begin{array}{l}\text { No } \\
\text { treatment }\end{array}$} & $\begin{array}{l}\text { Trimethoprim }+ \\
\text { sulfamethoxazole }\end{array}$ & PO & $1280 / 6400$ & $\begin{array}{l}1 \text { dose } 24 \text { hours before surgery }+2 \\
\text { doses/day for } 7 \text { days from surgery }\end{array}$ \\
\hline & & & & & $\begin{array}{l}\text { Methenamine } \\
\text { hippurate }\end{array}$ & PO & 8000 & $\begin{array}{l}1 \text { dose } 24 \text { hours before surgery }+3 \\
\text { doses/day for } 7 \text { days from surgery }\end{array}$ \\
\hline Rigatti & 1989 & ESWL & 120 & $\begin{array}{l}\text { No } \\
\text { treatment }\end{array}$ & Aztreonam & IM & 3000 & $\begin{array}{c}3 \text { doses beginning } 8 \text { hours before } \\
\text { surgery }\end{array}$ \\
\hline
\end{tabular}

dence of fever (RR $0.26,95 \% \mathrm{Cl}, 0.06$ to $1.10, p=0.07$ ). No adverse events related to antibiotic prophylaxis were recorded in these studies. The overall quality of evidence was moderate as judged by the GRADE criteria.

\section{Antibiotic class}

Fluoroquinolones were the most commonly studied antibiotics (3 trials). Third-generation, second-generation and first-generation cephalosporins, penicillin, aminoglycosides and sulfa-based antibiotics were each studied once. Studies varied in terms of dose, route and timing of administration in the treatment arms.

\section{Guideline recommendations}

Pre-procedural antibiotics do not significantly reduce the risk of UTI and fever in patients undergoing ESWL, but should be considered in patients at high risk of infectious complications (Grade B, Level of Evidence IB). Patients with large stone burden, associated pyuria, history of pyelonephritis, and adjunctive operative procedure including stent, nephrostomy insertion, PCNL or ureteroscopy are at a higher risk of developing pyelonephritis post-ESWL. ${ }^{2}$ The choice of specific agent for prophylaxis should be based, in part, on the local epidemiology of drug resistance in potential uropathogens (Grade D, Level of Evidence IV).

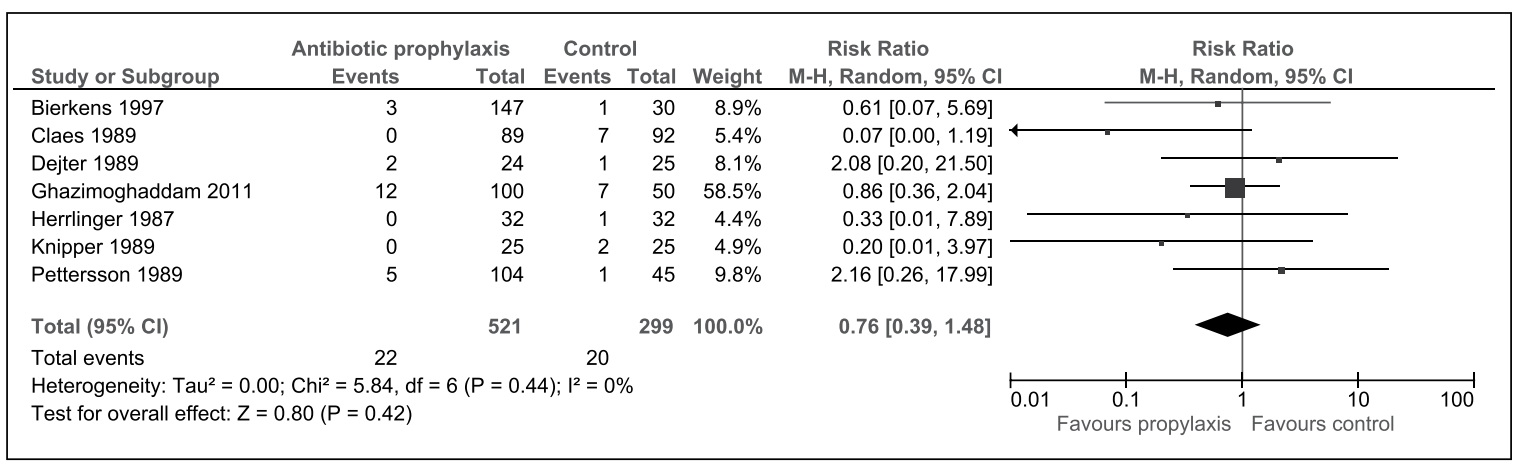

Fig. 2. Forest plot of relative risk of urinary tract infection with antibiotic prophylaxis for extracorporeal shock wave lithotripsy. 


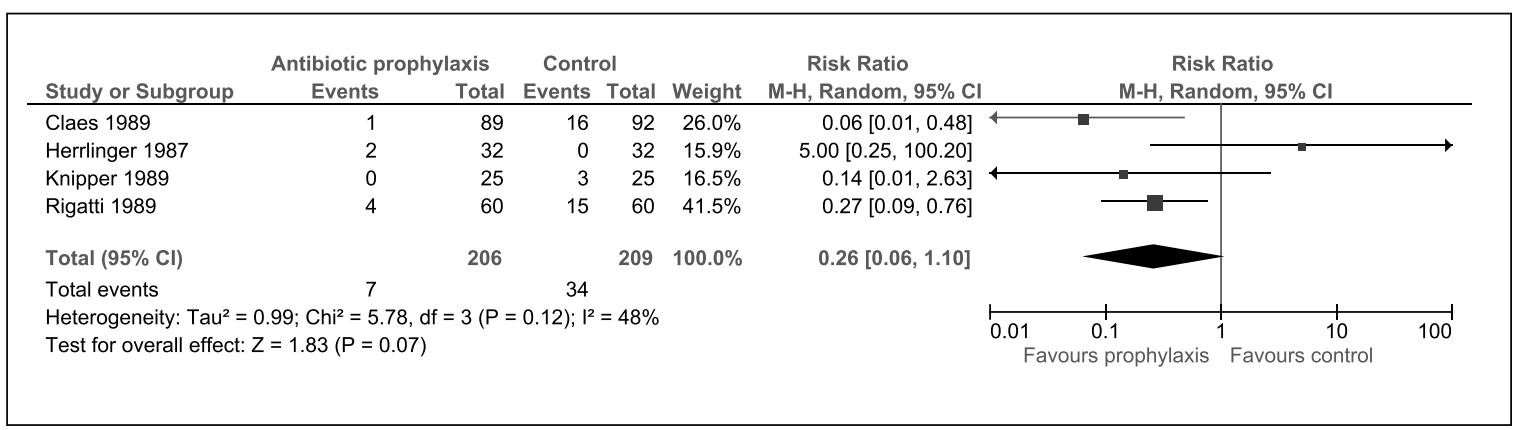

Fig. 3. Forest plot of relative risk of fever with antibiotic prophylaxis for extracorporeal shock wave lithotripsy.

\section{Antibiotic prophylaxis for stone manipulation procedures}

\section{Methods of literature search}

We included all RCTs comparing the use of antibiotic prophylaxis versus control. Study participant inclusion criteria involved adults with preoperative sterile urine who underwent PCNL, percutaneous stone removal or ureteroscopic stone removal. We excluded participants with positive preoperative urine cultures. The primary outcomes of interest were postoperative infectious complications of UTI, fever, or any other serious infectious complication. We excluded trials that did not report on these outcomes of interest.

\section{Results of systematic review}

The literature search identified 1450 citations, and we selected 47 articles for full-text retrieval (Fig. 1). Of the 54 articles, 4 met the eligibility criteria for final inclusion in the systematic review: 2 trials studied ureteroscopy, ${ }^{16,17} 1$ trial studied PCNL ${ }^{18}$ and 1 studied both ureteroscopy and PCNL. ${ }^{19}$ The 5 controlled trials randomized a total of 448 study participants (Table 2), with 349 patients having ureteroscopy and 99 patients having PCNL.

The incidence of UTI and fever in the non-antibiotic groups were $33.4 \%$ and $21.7 \%$, respectively. Antibiotic prophylaxis in patients undergoing non-ESWL stone manipulation procedures (Fig. 4, Fig. 5) was associated with a statistically significant difference in the risk of post-procedural UTI
(RR $0.30,95 \% \mathrm{Cl}, 0.15$ to $0.58, p<0.001$ ), but was not associated with a significant reduction in the incidence of fever (RR 0.38, 95\% Cl, 0.12 to 1.21, $p=0.10$ ). No adverse events related to antibiotic prophylaxis were recorded in these studies. The overall quality of evidence was moderate as judged by GRADE criteria.

\section{Antibiotic class}

Fluoroquinolones were studied in 2 trials, third-generation cephalosporins, first-generation cephalosporins, and aminoglycosides were each examined in single trials. Study interventions varied in terms of dose, route and timing of administration in the treatment arms.

\section{Guideline recommendations}

Antibiotics reduce the risk of UTI following non-ESWL stone manipulation procedures, and there is a trend towards a reduction in the incidence of fever. We recommend that peri-procedural antibiotics should be considered in patients undergoing ureteroscopy and PCNL (Table 2) (Grade A, Level of Evidence IA). The choice of specific agent for prophylaxis should be based, in part, on the local epidemiology of drug resistance in potential uropathogens (Grade D, Level of Evidence IV).

\begin{tabular}{|c|c|c|c|c|c|c|c|c|}
\hline Author & Year & Procedure & $\mathbf{N}_{\text {tot }}$ & Control & Antibiotic & Route & $\begin{array}{c}\text { Total dose } \\
\text { (mg) }\end{array}$ & Dosing Regimen \\
\hline Aghamir & 2011 & TUL & 114 & No treatment & Cefazolin & IV & 1,000 & 1 dose 1 hour before surgery \\
\hline Fourcade & 1990 & TUL \& PCNL & 120 & Placebo & Cefotaxime & IV & 1,000 & 1 dose at induction \\
\hline Pertek & 1992 & PCNL & 50 & Placebo & Amikacin & IV & $22.5 \mathrm{mg} / \mathrm{kg}$ & $\begin{array}{l}1 \text { dose } 12 \text { hours before surgery }+1 \text { dose at } \\
\text { induction }+1 \text { dose } 12 \text { hours after surgery }\end{array}$ \\
\hline Sobek & 1994 & TUL & 51 & No treatment & Ciprofloxacin & IV & 300 & $\begin{array}{c}1 \text { dose } 1 \text { hour before surgery }+1 \text { dose after } \\
\text { surgery }+1 \text { dose the day after surgery }\end{array}$ \\
\hline
\end{tabular}


Mrkobrada et al.

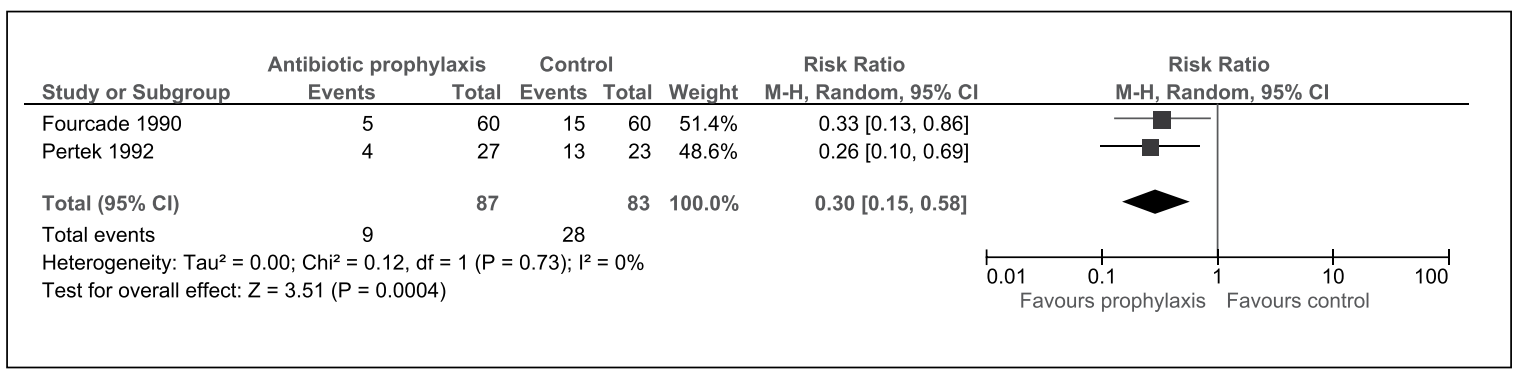

Fig. 4. Forest plot of relative risk of urinary tract infection with antibiotic prophylaxis for non- extracorporeal shock wave lithotripsy stone manipulation procedures.

\section{Antibiotic prophylaxis for urologic endoscopic procedures excluding treatment of renal calculi}

\section{Results of literature search}

We included all RCTs comparing the use of antibiotic prophylaxis versus control. Study participant inclusion criteria involved adults with sterile urine analyses who underwent endoscopic urologic procedures (cystoscopy, urodynamic studies or transurethral resection of the bladder tumour [TURBT]). Although there is a lack of literature regarding retrograde pyelography and stent insertions and I urethrotomy, the authors believe that the need for peri-procedural prophylaxis would be addressed by the guidelines in this section. Studies that included participants with positive preoperative urine cultures were excluded. The primary outcomes of interest were postoperative infectious complications of $\mathrm{UTI}$, fever, or any other serious infectious complication. We excluded trials that did not report on these outcomes of interest.

The literature search identified 4946 citations, and we selected 140 articles for full-text retrieval (Fig. 6). Of the 140 articles, 4 met the eligibility criteria for final inclusion in the systematic review. ${ }^{20-23}$ One trial addressed cystoscopy, and 3 trials addressed urodynamic studies. Although we did seek to include trials of antibiotic prophylaxis before TURBT procedures, we did not identify any trials that met our inclusion criteria.

\section{Results of the systematic review}

The 4 trials randomized a total of 2556 study participants (Table 3). There was a high incidence of adverse infectionrelated events in patients undergoing endoscopic urologic or catheter manipulation procedures without antibiotic prophylaxis, as UTI was documented in $10.9 \%$ of patients. Fever was not reported as an outcome in any trial.

Antibiotic prophylaxis use in patients undergoing endoscopic urologic procedures was associated with a strong trend towards a decrease in the risk of UTIs (Fig. 7), although the $95 \%$ confidence intervals did cross the line of unity (RR $0.42,95 \%$ confidence interval $[\mathrm{Cl}] 0.18$ to $1.01, p=0.05$ ). No adverse events related to antibiotic use were reported. The overall quality of evidence was moderate as judged by the GRADE criteria.

\section{Antibiotic class}

Fluoroquinolones ( 1 trial), trimethoprim ( 1 trial) and ceftriaxone ( 1 trial) were studied, and all studies showed a trend towards a decreased risk of post-procedural UTI.

\section{Guideline recommendations}

Pre-procedural antibiotics show a strong trend towards reducing the risk of $\mathrm{UTI}$, but not fever, after endoscopic urologic procedures. No adverse events associated with antibiotics were reported. Pre-procedural antibiotics should

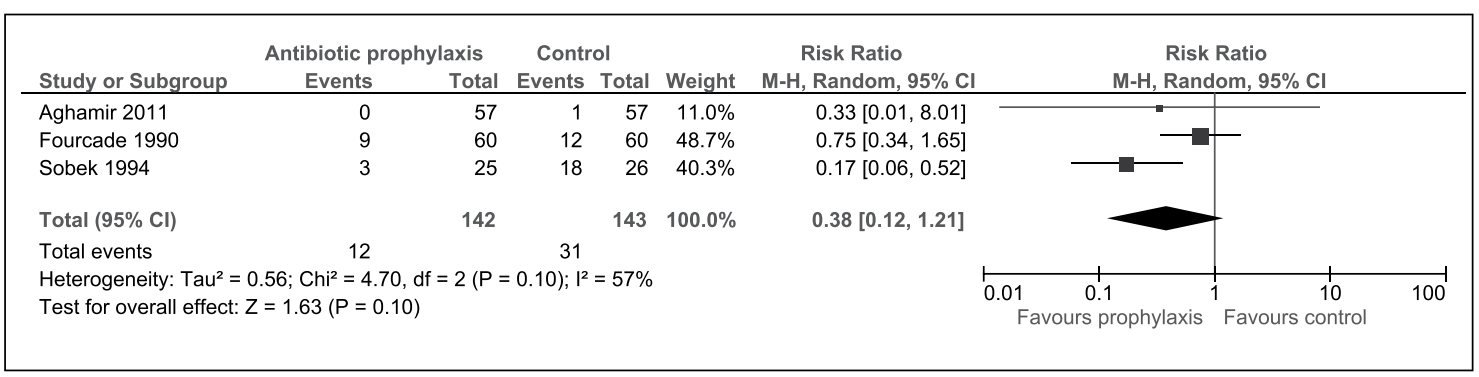

Fig. 5. Forest plot of relative risk of fever with antibiotic prophylaxis for non- extracorporeal shock wave lithotripsy stone manipulation procedures. 
CUA Guidelines on antibiotic prophylaxis

\begin{tabular}{|c|c|c|c|c|c|c|c|c|}
\hline Author & Year & Procedure & $\mathbf{N}_{\text {tot }}$ & Control & Antibiotic & Route & $\begin{array}{l}\text { Total dose } \\
(\mathbf{m g})\end{array}$ & Dosing regimen \\
\hline Coptcoat & 1988 & $\begin{array}{l}\text { Urodynamic } \\
\text { study }\end{array}$ & 82 & No treatment & Trimethoprim & PO & 200 & Prior to procedure \\
\hline Darouiche & 1994 & $\begin{array}{l}\text { Urodynamic } \\
\text { study }\end{array}$ & 40 & Placebo & Ciprofloxacin & PO & 3000 & $\begin{array}{c}\text { Twice daily for } 3 \text { days, starting } 2 \text { days } \\
\text { before procedure }\end{array}$ \\
\hline Jimenez Cruz & 1993 & Cystoscopy & 2172 & No treatment & Ceftriaxone & IM & 1000 & Prior to procedure \\
\hline Siracusano & 2008 & $\begin{array}{l}\text { Urodynamic } \\
\text { study }\end{array}$ & 262 & Placebo & Norfloxacin & PO & 400 & 12 hours before procedure \\
\hline
\end{tabular}

be considered in patients at high risk of infectious complications (Grade C, Level of Evidence IB). The choice of specific agent for prophylaxis should be based, in part, on the local epidemiology of drug resistance in potential uropathogens (Grade D, Level of Evidence IV).

\section{Antibiotics for TURP}

\section{Results of literature search}

Our literature search identified a recently-published systematic review of high methodological quality. ${ }^{24}$ We based our recommendations on the findings of this systematic review.

\section{Results of the systematic review}

The systematic review identified a total of 28 trials (4694 patients) comparing antibiotics versus placebo.

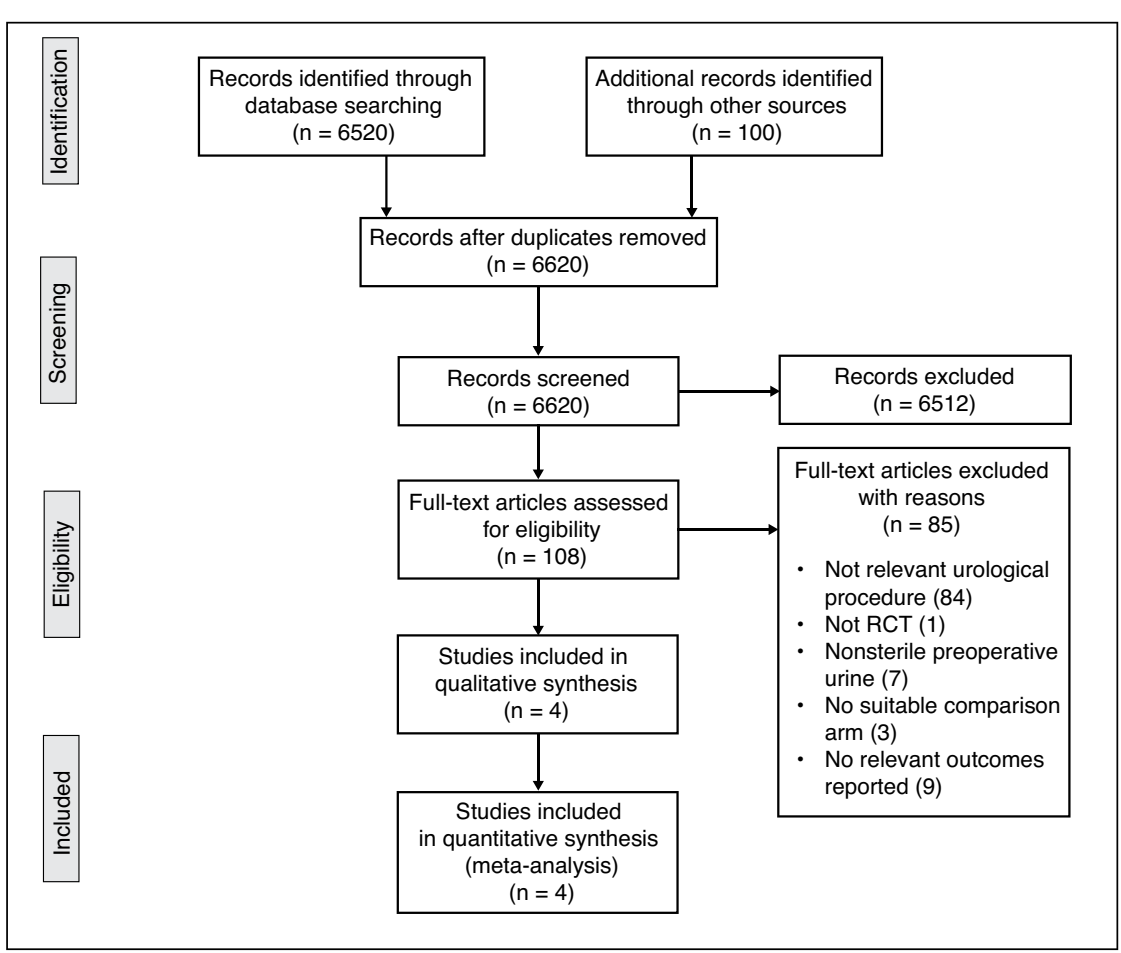

Fig. 6. Study selection flowsheet for urologic endoscopic procedures.
There was a high incidence of adverse infection-related events in patients undergoing TURP without antibiotic prophylaxis: bacteriuria in $23.4 \%$ of patients, bacteremia in $4.0 \%$ of patients, and fever in $26.9 \%$ of patients. Antibiotics significantly reduced the rates of bacteriuria (RR $0.34,95 \% \mathrm{Cl} 0.30$ to 0.40 ); bacteremia (RR $0.84,95 \% \mathrm{Cl} 0.71$ to 0.99 ) and fever (RR $0.25,95 \% \mathrm{Cl} 0.11$ to 0.56 ). No adverse events related to antibiotic prophylaxis were recorded in these studies.

Antibiotic class

In studies comparing different classes of antibiotics, there were no differences in outcomes. Third-generation cephalosporins were most frequently studied (9 trials).

\section{Guideline recommendations}

Due to the reduction in the risk of febrile UTI after TURP procedures, we recommend the use of prophylactic antibiotics prior to TURP (Table 4). (Grade A, Level of Evidence IA). The choice of specific agent for prophylaxis should be based, in part, on the local epidemiology of drug resistance in potential uropathogens (Grade D, Level of Evidence IV).

\section{Discussion}

After performing a comprehensive literature review, we have provided executive summaries on the best evidence supporting the use of prophylactic antimicrobials in common urologic procedures. All summaries specifically relate with patients with sterile preoperative urine cultures. If bacteria are found in the cultures, we strongly recommend preoperative eradication of the infection with a full course of antibiotics according to culture sensitivities.

The evidence suggests that antibiotics are useful for the prevention of fever and UTIs for most urologic surgeries and procedures. 
Mrkobrada et al.

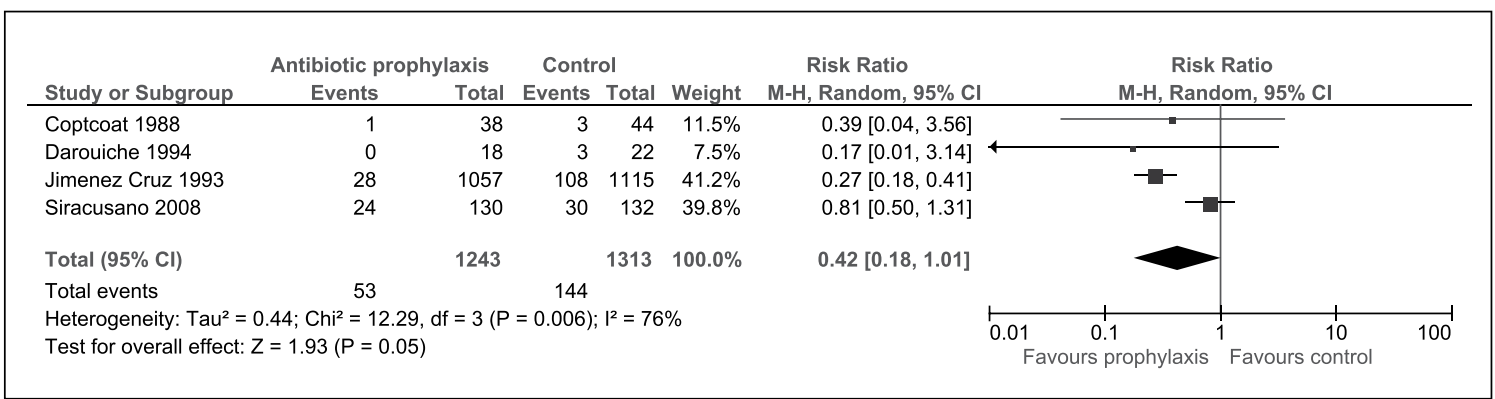

Fig. 7. Forest plot of relative risk of urinary tract infection with antibiotic prophylaxis for urologic endoscopic procedures.

\begin{tabular}{|c|c|c|c|c|c|}
\hline Author & $\mathbf{N}_{\text {tot }}$ & Antibiotic & Route & Dose (mg) & Dosing regimen \\
\hline Charton & 100 & Netilmicin & $\mathrm{IM}$ & 150 & 1 hour prior to surgery \\
\hline Childs & 47 & Ceftriaxone & IV & 1000 & 1 hour prior to surgery \\
\hline Desai & 40 & Enoxacin & IM & 200 & 1 dose $2-4$ hours prior and 3 doses postoperatively \\
\hline Fair & 61 & Carbenacillin & $\mathrm{PO} / \mathrm{IV}$ & $764 / 2000$ & $\begin{array}{c}\text { Night before surgery and QID for } 10 \text { days } \\
\text { IV during surgery }\end{array}$ \\
\hline Finklestein & 129 & Ceftriaxone & IV & 1000 & 1 hour prior to surgery \\
\hline Harvey & 162 & Cotrimoxazole & $\mathrm{PO}$ & 100 & After catheter removal for 10 days \\
\hline Nielsen & 10 & Cefoxitin & IM & 1000 & $\begin{array}{l}\text { 2-4 hours preoperatively and TID as long as catheter } \\
\text { remains }\end{array}$ \\
\hline Qvist & 88 & Cefotaxime & IV & 2000 & 1 hour prior to procedure \\
\hline Rocca Rosetti & 192 & Aztreonam & IV & 1000 & Prior to procedure and 2 doses postoperatively \\
\hline Slavis & 107 & Cefonicid & IM & 1000 & 1 hour prior \\
\hline Bannister & 61 & Septra, pivmecillinam & PO & 2 tablets $/ 200$ & $\begin{array}{c}\text { BID for } 3 \text { days postoperatively/TID for } 3 \text { days } \\
\text { postoperatively }\end{array}$ \\
\hline Botto & 167 & Cefotaxime & IV & 1000 & Prior and 2 doses post-procedure \\
\hline Charton & 100 & Mezlocillin & IV & 2000 & 1 hour prior to surgery \\
\hline Conn & 200 & Cephradine & IM & 1500 & $\begin{array}{c}1 \text { hour prior and } 1 \text { dose after surgery and } 1 \text { hour before } \\
\text { catheter removal }\end{array}$ \\
\hline Ferrie & 58 & Cefuroxime & IM & $1500 / 750$ & Before surgery and 6 doses postoperatively \\
\hline Gibbons & 100 & Kanamycin & IM & 500 & $\begin{array}{c}1 \text { hour prior and TID after surgery until catheter } \\
\text { removal }\end{array}$ \\
\hline Gonzalez & 90 & Cephalothin/Cephalexin & IV/PO & $1000 / 500$ & $\begin{array}{c}1 \text { dose preoperatively and } 4 \text { dose postoperatively/QID } \\
\text { for } 10 \text { days postoperatively }\end{array}$ \\
\hline Hargreave & 795 & Ceftazidime & IV & 1000 & Prior to procedure and daily until catheter removal \\
\hline Holl & 100 & Nitrofurantoin or Septra & $\mathrm{PO}$ & 1 tablet & 1 day prior and 10 days after catheter removal \\
\hline Houle & 110 & Cefoperazone & IV & 2000 & 1 day prior and 2 doses post-op \\
\hline Matthew & 87 & Nitrofurantoin & $\mathrm{PO}$ & 100 & $\begin{array}{c}6 \text { hours preoperatively and TID for } 10 \text { days } \\
\text { postoperatively }\end{array}$ \\
\hline Morris & 101 & Kanamycin/Septra & IM/PO & $1000 / 2$ tablets & 1 dose prior /BID for 3 weeks postoperatively \\
\hline Raz & 101 & Ceftriaxone & IV & 1000 & 1 dose prior and 1 dose prior to catheter removal \\
\hline Scholz & 139 & Ceftriaxone & IV & 1000 & 1-2 hours prior \\
\hline Stricker & 100 & Gentamicin/ Ampicillin & IV & $80 / 1000$ & 1 dose prior \\
\hline Taylor & 308 & Temocillin & IV & 1000 & 1 dose prior and 2 dose postoperatively \\
\hline Viitanen & 599 & Ceftriaxone/ Septra & IV/IV & $2000 / 800 / 160$ & 1 dose prior and 1 dose prior \\
\hline Weiss & 223 & Nitrofurantoin & $\mathrm{PO}$ & 200 & QID for 5-10 days postoperatively \\
\hline
\end{tabular}


Multiple classes of antibiotics were studied, although no class demonstrated superiority. The overall quality of literature supporting antibiotic use in general was moderate.

In this guideline, it would be remiss not to mention the stark lack of reporting of adverse outcomes, including drug toxicity, such as the development of Clostridium difficile colitis, and the development of antimicrobial drug resistance. Additionally, the American Heart Association no longer recommends urologic prophylaxis to prevent endocarditis in at-risk patients. ${ }^{25}$ The adoption of formal antimicrobial stewardship programs (ASPs) in many medical centres will serve to guide the judicious use of antimicrobials for urologic peri-procedural prophylaxis. ${ }^{26} \mathrm{ASP}$ activities in this regard should be based on a prospective audit and feedback mechanism, the use of antimicrobial order forms, dose optimization strategies, and formulary restriction or pre-authorization for specific procedures, with or without computerized support. The impact of the ASP strategies on patient safety and outcome must be continually evaluated. The decision to select a specific agent for prophylaxis will be based, in part, on the local epidemiology of drug resistance in potential uropathogens. The CUA recommends that the institution's microbiology/infectious disease team develop a formal ASP in developing preferred regimens for prophylaxis.

Although the duration of prophylaxis was not assessed in this review, the American Society of Health System Pharmacists, Infectious Diseases Society of America (IDSA), the Surgical Infection Society (SIS), and Society for Healthcare Epidemiology of America (SHEA) recommend a shorter periprocedural/perioperative course of antimicrobials involving a single dose or continuation for less than 24 hours. ${ }^{27}$ Risk factors for post-procedural infections may include obesity, extremes of age, nutritional status, diabetes mellitus, immunosuppressive therapy or immunosuppressed state. ${ }^{27}$

\section{Conclusion}

Although these guidelines were created to influence clinical decisions on a day to day basis, it is important to consider the impact of antibiotic use on our medical system and our individual patients.

Competing interests: Dr. Mrkobrada, Dr. Ying, Dr. Mokrycke, Dr. Dresser, Dr. Elsayed, Dr. Bathini, Dr. Boyce and Dr. Luke all declare no competing financial or personal interests.

This paper has been peer-reviewed.

\section{References}

1. Bratzler DW, Houck PM; and the Surgical Infection Prevention Guideline Writers Workshop. Antimicrobial prophylaxis for surgery: An advisory statement from the National Surgical Infection Prevention Project. Am J Surg 2005;189:395-404. http://dx.doi.org/10.1016/i.amisurg.2005.01.015

2. Wolf Jr JS, Bennett CJ, Dmochowski RR, et al. Best practice policy statement on urologic surgery antimicrobial prophylaxis. J Urol 2008;179:1379-90. http://dx.doi.org/10.1016/i.juro.2008.01.068

3. Moher D, Liberati A, Tetzlaff J, et al. Preferred reporting items for systematic reviews and meta-analyses: the PRISMA statement. Ann Intern Med 2009;151:264-9. http://dx.doi.org/10.7326/0003-4819151-4-200908180-00135

4. Guyatt GH, Oxman AD, Vist GE, et al. GRADE: An emerging consensus on rating quality of evidence and strength of recommendations. BMJ 2008;336:924-6. http://dx.doi.org/10.1136/bmi.39489.470347. $A D$

5. Zani EL, Clark 0, Rodrigues Netto Jr N. Antibiotic prophylaxis for transrectal prostate biopsy. Cochrane Database Syst Rev 2011;5.

6. Taylor AK, Zembower TR, Nadler RB, et al. Targeted antimicrobial prophylaxis using rectal swab cultures in men undergoing transrectal ultrasound guided prostate biopsy is associated with reduced incidence of postoperative infectious complications and cost of care. J Urol 2012;187:1275-9. http://dx.doi. org/10.1016/i.juro.2011.11.115

7. Adibi $M$, Hornberger $B$, Bhat $D$, et al. Reduction in hospital admission rates due to post-prostate biopsy infections after augmenting standard antibiotic prophylaxis. J Urol 2013;189:535-40. http://dx.doi. org/10.1016/i.juro.2012.08.194

8. Bierkens AF, Hendrikx AJ, Ezz el Din KE, et al. The value of antibiotic prophylaxis during extracorporeal shock wave lithotripsy in the prevention of urinary tract infections in patients with urine proven sterile prior to treatment. Eur Urol 1997;31:30-5.

9. Claes H, Vandeursen R, Baert L. Amoxycillin/clavulanate prophylaxis for extracorporeal shock wave lithotripsy-a comparative study. J Antimicrob Chemother 1989;24(Suppl B):217-20.

10. Dejter $S$, Abbruzzese $M$, Reid $B$, et al. Prospective randomized rvaluation of antimicrobial prophylaxis in patients undergoing extracorporeal shock wave lithotripsy. J Endourol 1989;3:43-6. http://dx.doi. org/10.1089/end.1989.3.43

11. Ghazimoghaddam B, Tajari H, Gholipoor M, et al. Antibiotic prophylaxis during extracorporeal shock wave lithotripsy (ESWL) in the prevention of urinary tract infections in patients with sterile urine before the procedure. J Clin Diagn Res 2011;5:772-4.

12. Herrlinger A, Bornhof C, Kuehn R. Antibiotic prophylaxis before extracorporeal shock wave lithotripsy by single-shot application of azlocillin. Chemioterapia 1987;6(2 Suppl):607-9.

13. Knipper A, Bohle A, Pensel J, et al. Antibiotic prophylaxis with enoxacin in extracorporeal shockwave lithotripsy [in German]. Infection 1989;17:S37-8. http://dx.doi.org/10.1007/BF01643635

14. Pettersson B, Tiselius HG. Are prophylactic antibiotics necessary during extracorporeal shockwave lithotripsy? Br J Urol 1989;63:449-52. http://dx.doi.org/10.1111/i.1464-410X.1989.tb05932.x

15. Rigatti P, Montorsi F, Guazzoni $G$, et al. Antibiotic prophylaxis with aztreonam in patients with kidney stone disease submitted to extracorporeal shock wave lithotripsy. J Chemother 1989;1 (4 Suppl):1017-8.

16. Aghamir $S M$, Hamidi $M$, Salavati $A$, et al. Is antibiotic prophylaxis necessary in patients undergoing ureterolithotripsy? Acta Med Iran 2011;49:513-6.

17. Sobek $M$, Kontarova $M$, Goncalves F. Prophylaxis with ciprofloxacin in transurethral surgery [in Slovak]. Rozhl Chir 1994:73:298-9.

18. Pertek JP, Junke E, Coissard A, et al. Penile block in adults [in French]. Ann Fr Anesth Reanim 1992;11:827.

19. Fourcade RO. Antibiotic prophylaxis with cefotaxime in endoscopic extraction of upper urinary tract stones: a randomized study. The Cefotaxime Cooperative Group. J Antimicrob Chemother 1990;26(Suppl A):77-83.

20. Coptcoat M, Reed C, Cumming J, et al. Is antibiotic prophylaxis necessary for routine urodynamic investigations?: A controlled study in 100 patients. Br J Urol 1988;61:302-3. http://dx.doi.org/10.1111/ i.1464-410X.1988.tb13962.x

21. Darouiche R, Smith M, Markowski J. Antibiotic prophylaxis for urodynamic testing in patients with spinal cord injury: A preliminary study. J Hosp Infect 1994;28:57-61. http://dx.doi.org/10.1016/0195$6701(94) 90153-8$

22. Jimenez Cruz JF, Sanz Chinesta $S$, et al. Antimicrobial prophylaxis in urethrocystoscopy. Comparative study [in Spanish]. Actas urologicas espanolas 1993;17:172-5.

23. Siracusano $S$, Knez $R$, Tiberio $A$, et al. The usefulness of antibiotic prophylaxis in invasive urodynamics in postmenopausal female subjects. Int Urogynecol J 2008;19:939-42. http://dx.doi.org/10.1007/ s00192-008-0570-6

24. Qiang W, Jianchen W, MacDonald R, et al. Antibiotic prophylaxis for transurethral prostatic resection in men with preoperative urine containing less than 100,000 bacteria per ml: A systematic review. J Urol 2005;173:1175-81. http://dx.doi.org/10.1097/01.ju.0000149676.15561.cb 
Mrkobrada et al.

25. Wilson W, Taubert KA, Gewitz M, et al. Prevention of infective endocarditis: guidelines from the American Heart Association: A guideline from the American Heart Association Rheumatic Fever, Endocarditis, and Kawasaki Disease Committee, Council on Cardiovascular Disease in the Young, and the Council on Clinical Cardiology, Council on Cardiovascular Surgery and Anesthesia, and the Quality of Care and Outcomes Research Interdisciplinary Working Group. Circulation 2007;116:1736-54. http://dx.doi.org/10.1161/ CIRCULATIONAHA.106.183095

26. Wagenlehner FM, Bartoletti R, Cek M, et al. Antibiotic stewardship: A call for action by the urologic community. Eur Urol 2013;64:358-60. http://dx.doi.org/10.1016/i.eururo.2013.05.044
27. Bratzler DW, Dellinger EP, Olsen $K M$, et al. Clinical practice guidelines for antimicrobial prophylaxis in surgery. Am J Health Syst Pharm 2013;70:195-283. http://dx.doi.org/10.2146/aihpl20568

Correspondence: Dr. Patrick Luke, 339 Windermere Rd, P0 Box 5339, London ON N6A 5A5; patrick.luke@lhsc.on.ca 